\title{
Appendicovaginal Fistula- A Rare Presentation of Mucinous Adenocarcinoma of Appendix
}

\author{
Harisankar Ananthapurath Girijavallaban ${ }^{1}$, Sreejayan Meethale Purayil ${ }^{2}$ \\ ${ }^{1}$ Senior Resident, Department of General Surgery, Government Medical College, Kozhikode, Kerala, India. \\ ${ }^{2}$ Professor, Department of General Surgery, Government Medical College, Kozhikode, Kerala, India.
}

\section{PRESENTATION OF CASE}

A 78 yrs., old female patient presented with history of recurrent right lower abdominal pain and burning micturition since 3 months. She had an episode of foulsmelling vaginal discharge 10 days back. She had undergone abdominal hysterectomy and bilateral salpingo-oophorectomy for adenomyosis 26 years back and vaginal vault repair for cystocele 4 years back. She is known hypertensive and is on antihypertensive medication for past 10 years. A full review of systems was otherwise negative, including the absence of haematochezia, melena, nausea, vomiting, appetite change and weight loss. She had an unremarkable abdominal examination, including the absence of tenderness to palpation, palpable masses, and peritoneal signs. Laboratory investigation revealed ESR $80 \mathrm{~mm} / \mathrm{hr}$, with $\mathrm{Hb} 9.9$ $\mathrm{gm} / \mathrm{dl}$ and normal total count. URE done was normal.

Colonoscopy revealed diminutive polyps in sigmoid colon from which biopsy was taken. No mass lesion/ulceration were observed. Ascending and descending colon were found to be normal. CT Scan (both plane and contrast) revealed $20 \mathrm{~mm}$ dilated inflamed appendix with minimal vaginal fluid and enhancing wall thickening of vaginal vault with apparent fistulous connection between appendicular tip and vaginal vault. MRI confirmed the above findings.

\section{CLINICAL DIAGNOSIS}

Acute appendicitis.

\section{DIFFERENTIAL DIAGNOSIS}

- Pelvic inflammatory disease

- Pelvic abscess

\section{DISCUSSION OF MANAGEMENT}

She underwent laparoscopy. Intraoperatively appendix base was friable; tip was perforated with a fistulous tract with the vaginal vault. Appendicectomy was done and fistulous tract was excised, and vaginal vault opening was closed. There was no intraperitoneal deposits or lymph nodes. Since gross and microscopic pathological examination revealed mucinous adenocarcinoma of appendix, she underwent laparotomy. Intraoperatively there were serosal nodules over the cecum and multiple mesenteric lymph nodes. Hemicolectomy was done with ileotransverse side to side anastomosis.
Corresponding Author:

Dr. Harisankar Ananthapurath Girijavallaban,

Siva Ponnayil House,

Anathapurath Lane,

Thammanam P. O., Cochin-682032,

Kerala, India.

E-mail: harisankar099@gmail.com

DOI: $10.14260 / \mathrm{jemds} / 2019 / 612$

Financial or Other Competing Interests: None.

How to Cite This Article: Girijavallaban HA, Purayil SM. Appendicovaginal fistula- a rare presentation of mucinous adenocarcinoma of appendix. J. Evolution Med. Dent. Sci. 2019;8(36):2823-2825, DOI: $10.14260 /$ jemds/2019/612

Submission 06-07-2019,

Peer Review 21-08-2019,

Acceptance 28-08-2019,

Published 09-09-2019. 


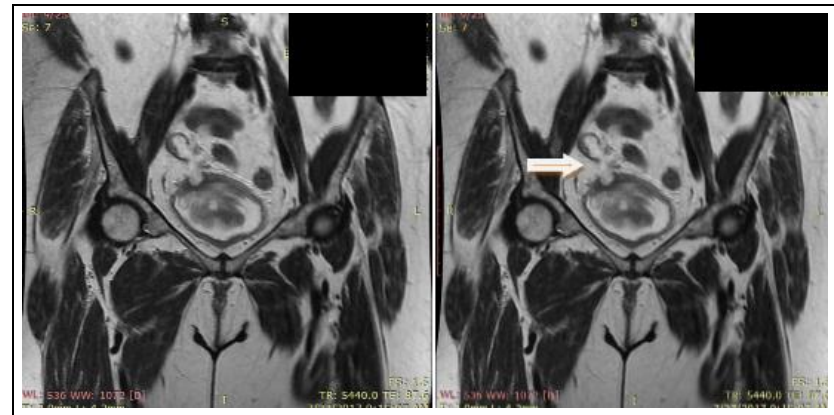

Figure 1. MRI Showing Appendicovaginal Fistula

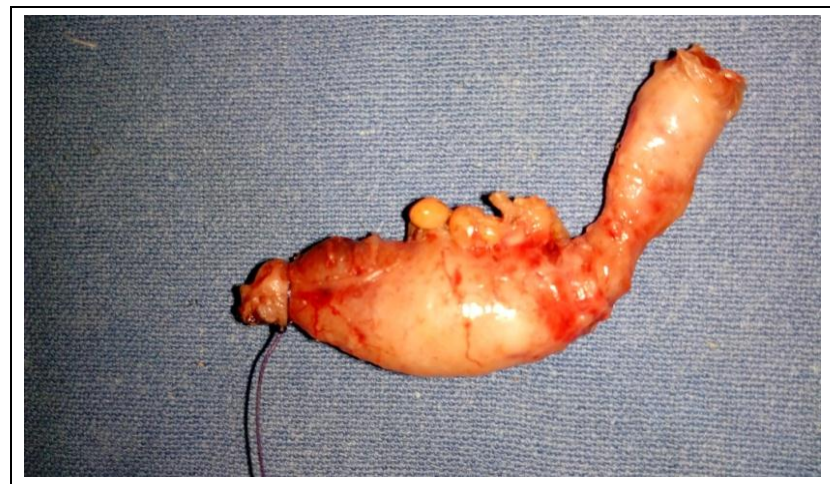

Figure 2a. Appendicectomy Specimen Showing Tip Perforated with Appendicovaginal Fistula Remnant at the Tip

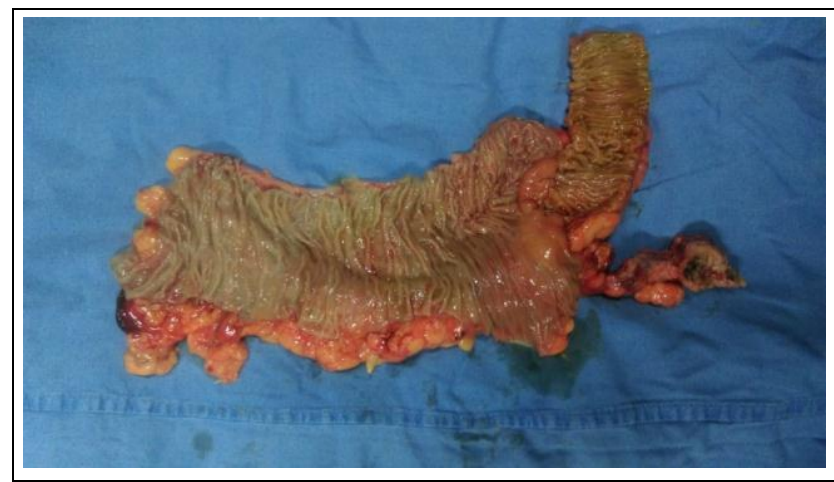

Figure 2c. Hemicolectomy Specimen. Appendix Stump can be Seen
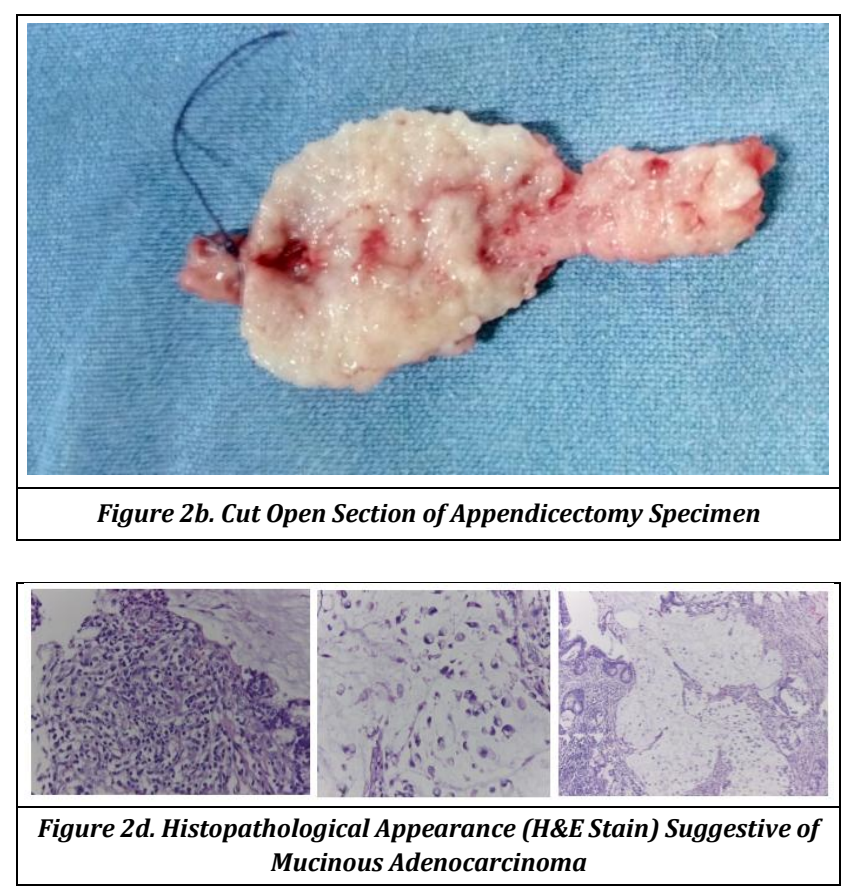

\section{PATHOLOGICAL DISCUSSION}

Gross and microscopic pathological examination revealed mucinous adenocarcinoma of appendix. Further pathological examination of hemicolectomy specimen revealed mucinous adenocarcinoma of appendiceal stump with few signet ring cells. Focal tumour deposits in the caecal subserosa with mesenteric deposits. Fistulous tract also showed malignant cells. 1/11 lymph node was found to have metastasis.

\section{DISCUSSION}

Primary adenocarcinoma of the appendix is rare condition. It accounts for 0.12 cases per 1000000 patients per annum, $0.05 \%-0.2 \%$ of all appendectomies, about $0.2 \%$ of all gastrointestinal neoplasms, and only $6 \%$ of appendiceal cancers. $(1,3)$ The typical patient is older, and duration of symptom is usually longer.(1) There are four major histological subtypes of appendiceal adenocarcinoma: cystic, colonic, carcinoid, and adeno-carcinoid. Carcinoids are the most common, comprising nearly $90 \%$ of all primary appendiceal tumours while mucinous cystadenocarcinoma is the second most common type.(2) Appendiceal adenocarcinoma is further divided into colonic, mucinous (MAA), goblet cell, and signet ring cell types. $(3,4)$ Primary signet ring cell carcinoma of the appendix is an exceedingly rare entity, comprising only $4 \%$ of all appendiceal neoplasms

MAA usually presents with nonspecific findings. It frequently presents with acute abdominal pain resembling acute appendicitis; sometimes presents as an abdominal mass detected by palpation or abdominal imaging rarely presents with nausea, vomiting, ascites, or involuntary weight loss.(5,6,7) Due to its nonspecific presentation malignancy of the appendix are never diagnosed preoperatively and seldom intra operatively, the diagnosis being usually made at histopathological examination of the surgical specimen or as an incidental finding during exploration for another disease.(6) MAA usually a non-invasive, low grade malignancy with less chance of distant metastasis. However, the signet ring type is high grade with chance of metastasis. Unfortunately, our case has few signet ring cells which is a rare entity.(8)

MAA frequently causes appendiceal perforation attributed to the mucinous gel obstructing the lumen and the narrow appendiceal lumen. ${ }^{(9,10)}$ Details regarding the therapy for MAA is sparse. Surgical management is the mainstay. Right hemicolectomy is done when appendicectomy specimen reveals Adenocarcinoma.(11)

CT Abdomen and pelvis and colonoscopy are essential before doing hemicolectomy to rule out metachronous/ synchronous lesions.

Presence of peritoneal spread requires surgical debulking by primary tumor excision, right hemicolectomy, lymph node dissection, omentectomy, peritoneotomy, and removal of malignant ascites. Patients with intraperitoneal lymphadenopathy or PMP benefit from adjuvant intraperitoneal hyperthermic chemotherapy. The drugs used intraoperatively for hyperthermic chemotherapy are mitomycin (Mutamycin), cisplatin, and doxorubicin or oxaliplatin (Eloxatin). Most patients who receive heated 
intraoperative intraperitoneal chemotherapy are also given early postoperative intraperitoneal fluorouracil (5-FU) or paclitaxel.(12) There are studies where patient benefitted from 12 cycles of oxaliplatin, 5-fluorouracil, and leucovorin (FOLFOX-4).(12) Frequent colonoscopy is required after surgery since incidence of metachronous cancer is $17 \% .{ }^{(2)}$

\section{FINAL DIAGNOSIS}

Mucinous adenocarcinoma of appendix with appendicovaginal fistula.

\section{REFERENCES}

[1] McCusker ME, Coté TR, Clegg LX, et al. Primary malignant neoplasms of the appendix: a population-based study from the surveillance, epidemiology and end-results program, 1973-1998. Cancer 2002;94(12):3307-12.

[2] Connor SJ, Hanna GB, Frizelle FA. Appendiceal tumors: retrospective clinicopathologic analysis of appendiceal tumors from 7,970 appendectomies. Dis Colon Rectum 1998;41(1):75-80.

[3] Topkan E, Polat Y, Karaoglu A. Primary mucinous adenocarcinoma of appendix treated with chemotherapy and radiotherapy: a case report. Tumori 2008;94(4):5969.

[4] Bosman FT, Carneiro F, Hruban RH, et al. WHO classification of tumours of the digestive system. International Agency for Research on Cancer 2010;(3):1089.
[5] Gourgiotis S, Oikonomou C, Kollia P, et al. Persistent coughing as the first symptom of primary mucinous appendiceal adenocarcinoma. J Clin Med Res 2015;7 (8):649-52.

[6] Behera PK, Rath PK, Panda R, et al. Primary appendiceal mucinous adenocarcinoma. Indian J Surg 2011;73(2):146-8

[7] Ploenes T, Börner N, Kirkpatrick CJ, et al. Neuroendocrine tumour, mucinous adenocarcinoma and signet-ring cell carcinoma of the appendix: three cases and review of literature. Indian J Surg 2013;75(Suppl 1):299-302.

[8] Sirintrapun SJ, Blackham AU, Russell G, et al. Significance of signet ring cells in high-grade mucinous adenocarcinoma of the peritoneum from appendiceal origin. Hum Pathol 2014;45(8):1597-604.

[9] Cerame MA. A 25-year review of adenocarcinoma of the appendix. A frequently perforating carcinoma. Dis Colon Rectum 1988;31(2):145-50.

[10] Ronnett BM, Zahn CM, Kurman RJ, et al. Disseminated peritoneal adenomucinosis and peritoneal mucinous carcinomatosis. A clinicopathologic analysis of 109 cases with emphasis on distinguishing pathologic features, site of origin, prognosis and relationship to "pseudomyxoma peritonei”. Am J Surg Pathol 1995;19(12):1390-408.

[11] Ito $\mathrm{H}$, Osteen RT, Bleday $\mathrm{R}$, et al. Appendiceal adenocarcinoma: long-term outcomes after surgical therapy. Dis Colon Rectum 2004;47(4):474-80.

[12] Ko YH, Jung CK, Oh SN, et al. Primary signet ring cell carcinoma of the appendix: a rare case report and our 18year experience. World J Gastroenterol 2008;14 (37):5763-8. 